\title{
Levelling up International Higher \\ Education: Universities, Nations and \\ Global Goals
}

\author{
Jo Beall
}

\section{Introduction}

Universities are not only the anchors, shapers and innovators of nations but they galvanise the building and rebuilding of nations. They are a source of knowledge, an arena to develop understanding and provide the vehicles for interpreting and addressing the key challenges of our time. Nations need universities to develop home-grown solutions for the problems and opportunities with which they are presented, and so they can participate with value and confidence in international scientific eco-systems. Yet, national universities do not and should not act alone. Agenda 2030 and the Sustainable Development Goals constitute the principal international convention of our time and offer a positive step in recognising the importance of tertiary education to individual and social advancement. However, they do not go far enough, particularly from the vantage point of nations with ambitions to grow prosperous economies and engaged societies. This chapter explores the national and international role of universities and the benefits or otherwise of the internationalisation of higher education and global conventions such as Agenda 2030.

\section{Setting the Scene}

From time immemorial scholars have sought to exchange ideas and to collaborate across international boundaries. National science, understood in its broadest sense to include the humanities and social sciences, cannot and should not remain isolated from global scholarly debates and research endeavours. However, higher education is no longer simply the purview of curiosity-driven scholars engaging across borders.

\footnotetext{
J. Beall (凶)

London School of Economics and Political Science, London, UK

e-mail: j.beall@1se.ac.uk 
Over recent decades, higher education systems have become increasingly internationalised, and along with this trend, they often become more and more commercialised. For some time, this dramatically skewed the international higher education landscape. It did so in favour of universities that were part of established systems, largely in the advanced economies, which were able to dramatically expand their international teaching activities by literally trading on their histories and well-honed expertise.

Universities did this in two ways: by attracting international students to their doors and by delivering degrees abroad. Transnational education (TNE) has taken different forms from joint degrees and Ph.D. programmes offered in whole or in partnership with domestic institutions, through to the full-blown creating and running of branch campuses in new countries. In its best guise, it emphasises partnership and, in its worst, it is most usually associated only with profit. In assessing the impact of TNE, for European and North American institutions it helped them expand their reputation as well as their coffers at a time when they were experiencing declining domestic demand, due to a slow-down in population growth and demand for tertiary education. This suited many countries with smaller higher education systems that were nevertheless experiencing a growing demand for tertiary education due to population growth and greater prosperity.

The internationalisation of higher education is accompanied by both opportunities and challenges. Commercial drivers underpinning TNE demand constant vigilance on the part of host nations and potential students with regard to ensuring standards match those of home campuses and that the education they receive represents value for money. Difficult dynamics can also arise when domestic and international universities compete to secure for themselves the brightest and best academics and students in a country. Further, there are modus operandi that offer examples of better or worse practice. For instance, some universities work on the principle of equitable partnership in their teaching and research collaboration, while others focus primarily on their profit margins. For better or worse, national governments have been known to deliberately cultivate TNE in order to help improve their own standards or research reputations. Countries such as China and Singapore that have gone this route have fared very well, without sacrificing their autonomy and often periodically renegotiating the nature of their international agreements. In the process, their universities have steadily risen up the international league tables.

Universities have also contributed to local and regional development. Today, city and sub-national governments increasingly see universities as pivotal to local economic innovation systems, labour markets and social engagement with local communities and citizens. Universities, industry and local governments working together to create innovative partnerships can become international hubs and players on their own account. This is perhaps best exemplified by the role played by the Government of California and Stanford University in the development of Silicon Valley, but another perhaps less well-known example is Kuala Lumpur, which through national policy support has become an internationally recognised higher education hub that serves not only the country but the Association of South-East Asian Nations (ASEAN) region and beyond. As cities, nations and regions grow their own tal- 
ented knowledge-economy graduates, and as they participate as equals and leaders in international research eco-systems, we see the playing field of international higher education being levelled.

\section{Universities and Nation-Building}

It is against a background of these challenges and opportunities that today's national leaders seek to maintain a critical balance between keeping universities at the heart of their nation-building processes, while at the same time retaining with and for them, their international reputation and relevance. During the independence period in Africa, leaders such as Julius Nyerere and Kwame Nkrumah believed that higher education would be critical to the self-determination and economic development of post-independence countries. In this vein, in 1961 during his speech to the Council of the University of Ghana, Nkrumah said that the University of Ghana, newly independent from the University of London, had to contribute to national and regional development. He added an important caveat: in order to do that effectively and to retain respect, the University also had to remain internationally recognised and connected. Many universities globally have been fellow travellers in the wake of these wise words, to the benefit not only of their own countries but the wider world as well (Enders 2004: 367).

Historically, there has been strong acknowledgement that universities can and do play an important part in the process of nation-building, as custodians and generators of national culture. They do this particularly through the humanities, for example languages, history and the arts, but also through the sciences and the social sciences. In this way, they engage communities and promote political stability by actively contributing to the establishment of national cultures that underpin the formation and strengthening of nation-states. Importantly, it is international recognition from other nations that cements and strengthens national identities. Nkrumah recognised this, and leaders like himself ensured that universities would play a critical role, as newly independent countries sought to establish national systems and institutions in the post-colonial era.

Today, the expansion of international higher education and research partnerships are seen by many national governments as a means to deliver on national growth priorities. Universities are interactive institutions that work together with industry, commerce, government and communities and as such, became increasingly seen as integral to national innovation systems (Mowery and Sampat 2005). In many emerging markets, national and local governments explicitly link the internationalisation of higher education and research to economic development in their national planning processes (Altbach et al. 2009; Beall 2016). As such, state intervention in the field of international higher education and research is unlikely to disappear any time soon. The questions, therefore, are how internationalisation is conducted, who is involved and through what modalities? 


\section{International Conventions and Practices}

At the turn of the millennium, 189 nations made a promise to eradicate poverty across the world by 2015, a pledge that turned into the Millennium Development Goals (MDGs). While good progress was made for many of the MDGs, they were generally seen as unfinished business. The second goal was to 'achieve universal primary education', which was an important and worthy target, although one of the goals not met. Trying to meet the target led to reach being prioritised over quality of provision, but of greater relevance for present purposes was the fact that secondary and tertiary education were ignored. This was reflective of the global educational debates and development priorities in which the MDGs were located, but it also set the terrain for priorities going forward (Beall 2015). As a result, it was a real struggle to achieve a specific focus on higher education under the successor convention, Agenda 2030 and the Sustainable Development Goals (SDGs). Ultimately, however, a holistic and systemic approach to education was endorsed, rather than picking off primary schooling.

In addition to international policy conventions, there are membership bodies in international higher education that have flown the flag and, by definition, exhibit a commitment to principles of parity. Examples here would include the International Association of Universities (IAU), the Association of Commonwealth Universities (ACU) and the African Research Universities Alliance (ARUA). Yet, in looking at the ways in which institutions and system engage internationally, it is important to recognise that relationships are not built on a tabula rasa. Some institutions have been at it for centuries, while others are new to the table. Some faculty are more au fait with international and cross-cultural communication than others. And some countries are better resourced or choose to spend greater proportions of domestic income and savings on internationalising their higher education sectors.

In addressing inequities and imbalances, there are lessons to be learned. I will share just one here. INASP began as an Oxford-based charity that engaged scientific journals and prevailed upon them to offer journals at a highly subsidised rate to less privileged universities in low-income countries. Its brief grew to include programmes such as Author Aid, which helps academics and researchers from these same institutions and settings to get published, including a strong focus on gender disparities within them. Today, INASP is spearheading an international network committed to locally generated knowledge and solutions that are key to solving local and global challenges. As part of this, it supports government institutions in improving the use of research and evidence to inform policy so recourse does not always and only have to be made to bilateral and multinational organisations (INASP 2020). It is examples such as these that offer hope to nations struggling to establish viable and confident higher education systems for themselves, let alone trying to compete internationally, although we should also be clear that they too have much of value to share. All too often, the researchers from institutions with extensive libraries and equipment dominate in research projects and publications over local partners who have access to 'the field' and an understanding thereof. 


\section{Conclusion}

As we enter this unprecedented period in which our global present and future are being shaped by unknown viruses and burgeoning global discontent, learning from local knowledge and solutions drawn from all over the world has never been so important. The treatment and management of HIV/AIDS and Ebola in Africa can tell us much about how to handle global pandemics such as COVID-19. Rebelling against the legacy of colonialism and apartheid rule, South African students challenged those with enquiring minds everywhere to question the nature, source and purpose of knowledge. Calls for decolonising the curriculum are now heard on the streets of Britain as statues of slave traders tumble and fall. Never before has it been so important to answer the question, who owns the canon? The critical thinking and spirit of curious enquiry engendered by universities need to be front and centre not only of the building but also of the re-building of national identities. They are desperately needed to provide the intellectual spaces to forge the canon for the next seventy years of the IAU.

\section{References}

Altbach, P.G., Reisberg, L., \& Rumbley, L.E. (2009). Trends in global higher education: Tracking an academic revolution. Report prepared for the UNESCO World Conference on Higher Education. Beall, J. (2016). Universities and their importance to nations and cities. In M. Stiasny \& T. Gore (Eds.), Going Global: Connecting Cultures, Forging Futures (Vol. 5, pp. 219-231). London: Institute of Education Press.

Beall, J. (2015). Tertiary education: The unfinished business of the Millennium Development Goals. In M. Stiasny \& T. Gore (Eds.), Going Global: Inclusion, Innovation, Impact (Vol. 4,pp. 217-228). London: Institute of Education Press.

Enders, J. (2004). Higher education, internationalisation, and the nation-state: Recent developments and challenges to governance theory. Higher Education 47, 367.

INASP. (2020). INASP Strategic Plan, Oxford. Retrieved from: https://www.inasp.info (26.07.2020)

Mowery, D.C. \& Sampat, B.N. (2005). Universities in national innovation systems. In J. Fagerberg., D.C. Mowery \& R. Nelson (Eds.), The Oxford Handbook of Innovation (pp. 209-239). Oxford: Oxford University Press.

Jo Beall is Emeritus Professor and Distinguished Policy Fellow at the London School of Economics and Political Science (LSE). Formerly Director of Education and Society and on the Executive Board at the British Council, she was also Deputy Vice-Chancellor of the University of Cape Town (UCT) and before that a Professor of International Development at the LSE. She is currently involved in conducting research on urban services in Ethiopia and Pakistan. 
Open Access This chapter is licensed under the terms of the Creative Commons Attribution 4.0 International License (http://creativecommons.org/licenses/by/4.0/), which permits use, sharing, adaptation, distribution and reproduction in any medium or format, as long as you give appropriate credit to the original author(s) and the source, provide a link to the Creative Commons license and indicate if changes were made.

The images or other third party material in this chapter are included in the chapter's Creative Commons license, unless indicated otherwise in a credit line to the material. If material is not included in the chapter's Creative Commons license and your intended use is not permitted by statutory regulation or exceeds the permitted use, you will need to obtain permission directly from the copyright holder. 